ISSN 2236-0859

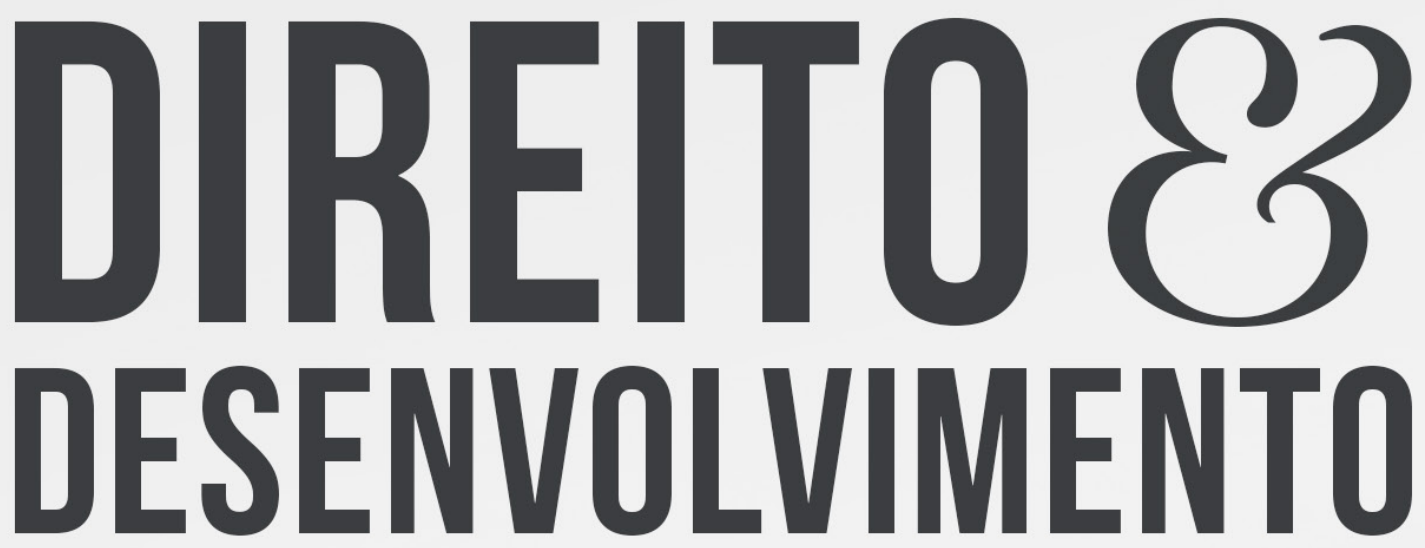

REVISTA DO PROGRAMA DE PÓS-GRADUAÇÃO EM DIREITO MESTRADO EM DIREITO E DESENVOLVIMENTO SUSTENTÁVEL

RESPONSABILIDADE COMPARTILHADANA POLITIICA NACIONAL DE RESÍDUOS SÓLIDOS: APLICABILIDADE DA NORMA TRIBUTÁRIA AMBIENTAL INDUTORA

MARIA MARCONETE FERNANDES PEREIRA

LEONARDO TELES DE OLIVEIRA 


\title{
RESPONSABILIDADE COMPARTILHADA NA POLÍTICA NACIONAL DE RESÍDUOS SÓLIDOS: APLICABILIDADE DA NORMA TRIBUTÁRIA AMBIENTAL INDUTORA
}

\section{SHARED RESPONSIBILITY IN THE NATIONAL SOLID WASTE POLICY: APPLICABILITY OF THE INDUSTRY TAX ENVIRONMENT}

Recebido: 06/12/2019

Aprovado: 12/12/2019
Maria Marconiete Fernandes Pereira ${ }^{1}$ Leonardo Teles de Oliveira ${ }^{2}$

\section{RESUMO:}

É inegável que, ao longo das últimas décadas, as transformações sociais muito contribuíram para o aumento da degradação dos ecossistemas. Em decorrência do consumismo exagerado instalouse uma verdadeira crise ecológica. Faz-se, então, necessário o desenvolvimento de estratégias eficazes, de modo a mobilizar a sociedade em defesa da proteção dos recursos naturais. Nesse sentido, a Constituição Federal já impõe algumas medidas à iniciativa privada e à sociedade. A instituição da política nacional de resíduos sólidos, através da Lei no 12.305/2010, pode ser um instrumento de responsabilidade compartilhada. Esse diploma legal prevê a integração dos setores público e privado, baseada na cooperação, mobilização e participação social. A questão é saber se essa estratégia pode ser considerada um marco na superação dos clássicos mecanismos de comando e controle predominantes. A citada lei permite a instituição de medidas indutoras tributárias, tais como a concessão de incentivos fiscais, econômicos e creditícios. Para a realização desta pesquisa, optou-se pelo método dedutivo e pela técnica da revisão bibliográfica. Após o estudo, confirmou-se a hipótese de que a utilização da extrafiscalidade tributária ganha relevo como forma de estímulo a comportamentos ambientalmente adequados às diretrizes da política nacional de resíduos sólidos.

Palavras-chave: Resíduos sólidos. Responsabilidade compartilhada. Taxa de coleta de resíduos sólidos.

\begin{abstract}
:
It is undeniable that, over the last decades, social transformations have greatly contributed to the further degradation of ecosystems. Due to the exaggerated consumerism, a true ecological crisis has set in. It is therefore necessary to develop effective strategies to mobilize society in defense of the protection of natural resources. In this sense, the Federal Constitution already imposes some measures on private initiative and society. The establishment of the national solid waste policy, through Law No. 12.305 / 2010, can be an instrument of shared responsibility. This legal diploma

\footnotetext{
1 Doutora em Direito Público pela UFPE. Mestre em Ciências Jurídicas pela UFPB. Professora Titular da graduação em Direito Tributário e de Administrativo do UNIPÊ. Professora do Programa de Pós-Graduação em Direito, Mestrado do Centro Universitário de João Pessoa/UNIPÊ. Email: maria.fernandes@unipe.edu.br

2 Mestrando em Direito e Desenvolvimento Sustentável pelo Centro Universitário de João Pessoa (UNIPÊ) e Procurador do Município de João Pessoa. Email: leonardoprogemjp@gmail.com
} 
provides for the integration of the public and private sectors, based on cooperation, mobilization and social participation. The question is whether this strategy can be considered a milestone in overcoming the prevailing classic command and control mechanisms. The aforementioned law allows the imposition of tax-inducing measures, such as the granting of fiscal, economic and credit incentives. For this research, we opted for the deductive method and the literature review technique. After the study, the hypothesis was confirmed that the use of tax extrafiscality becomes relevant as a way of stimulating behaviors that are environmentally appropriate to the guidelines of the national solid waste policy.

Keywords: Solid waste. Shared responsibility. Solid waste collection rate.

\section{INTRODUÇÃO}

As atividades humanas impactam diretamente o meio ambiente como resultado das complexas necessidades da sociedade contemporânea. Em consequência, são produzidas diariamente, grandes quantidades de resíduos produzidos nos centros urbanos.. A questão envolve o comportamento humano em relação à preservação do meio ambiente. Daí a necessidade de se desenvolverem métodos para estimular a redução de danos ambientais ocasionados pelo consumismo.

O legislador brasileiro tratou da temática protecionista ambiental como uma responsabilidade compartilhada por toda a sociedade, incluindo-a também, como agenda política dos entes federados. A Lei no 12.305, de 03 de agosto de 2010, institui a política nacional de resíduos sólidos (PNRS), com o propósito de traçar diretrizes, instrumentos, metas e ações. O objetivo é estimular uma gestão integrada para fins de gerenciamento ambientalmente adequado dos resíduos sólidos. É consenso que um dos maiores problemas ambientais da atualidade é a produção desenfreada e o manejo inadequado dos resíduos sólidos.

A responsabilidade compartilhada envolve o ciclo de vida dos produtos promovendo a união de interesses entre os agentes econômicos e sociais. Esses agentes podem integrar a iniciativa privada (fabricantes, importadores, distribuidores e comerciantes), podem ser os responsáveis pelos serviços públicos de manejo de resíduos sólidos, consumidores e gestores públicos. Busca-se, com essas estratégias, implementar processos instrumentais de redução dos impactos no meio ambiente.

Um dos instrumentos econômicos adotado pelo Estado seria efetivado por meio de normas tributárias indutoras, como a extrafiscalidade tributária. Com sua implementação, é possível alterar os custos de utilização de recursos naturais, reduzindo os danos ambientais. A intervenção econômica do Estado busca a promoção de uma concreta internalização das externalidades ambientais negativas. Pretende, especialmente, a materialização do princípio do poluidor pagador, de modo a induzi-lo a realizar suas atividades em níveis ecologicamente desejáveis. Essa medida governamental pretende superar os mecanismos de comando e controle daquela postura repressiva no combate à degradação ambiental.

Com a adoção da política nacional de resíduos sólidos, busca-se quebrar esse paradigma relacionado à antiga postura repressiva estatal. Dessa forma, pretende-se valorizar a indução indireta de condutas, como meio eficaz para o alcance das diretrizes e objetivos legalmente fixados. Nesse contexto, foram utilizadas, como exemplo, as taxas de coleta de resíduos sólidos que, ainda, em grande parte, são revestidas de característica meramente retributiva, quando poderiam potencializar estímulos a comportamentos preservacionistas. 
A interação entre a intervenção indutora do Estado e o meio ambiente reflete a capacidade de disciplinamento da atividade econômica, que passa, necessariamente pelo Direito nessa conjuntura da contemporaneidade. Expressa-se, no entanto, pela pretensão do Poder Legislativo em estimular os comportamentos ambientalmente desejados dos stakeholders. Na tentativa de disciplinar esses comportamentos, o sistema jurídico possui a capacidade necessária de implementá-los por meio de comandos legislativos.

Com base nesse pressuposto, o presente artigo tem por objetivo responder ao seguinte questionamento: A Lei no 12.305/2010, que instituiu a gestão e o gerenciamento integrados de resíduos, pode ser considerada um marco na superação dos clássicos mecanismos de comando e controle, conferindo destaque aos instrumentos econômicos, a exemplo da extrafiscalidade tributária? Partindo-se dessa hipótese, infere-se que a política nacional de resíduos sólidos pode ser considerada uma baliza normatizadora da superação da clássica postura corretivarepressiva do Estado, possuindo potencial a adoção de ferramentas vinculadas à concessão de incentivos fiscais, financeiros e creditícios. Uma das estratégias é a extrafiscalidade tributária, materializada na taxa de coleta de resíduos sólidos. É inegável seu poder de estimular a redução na excessiva produção de lixo.

No desenvolvimento desta abordagem, adotou-se o método dedutivo, partindo-se da hipótese de que a nova ordem jurídica ambiental, com a instauração da política nacional de resíduos sólidos, promove a interação dos agentes econômicos por meio da responsabilidade compartilhada. Há execução dessa medida, pode ser aplicada a extrafiscalidade tributária como instrumento econômico de proteção ambiental. Com base nesse pressuposto, far-se-á uma análise do marco normatizador da política nacional de resíduos sólidos. Discutir-se-á, especialmente, a instauração da gestão e do gerenciamento integrados de resíduos como estratégia da suplantação dos mecanismos de comando e controle por parte do poder público, quando se permite a promoção de normas tributárias indutoras para dirimir externalidades negativas ambientais.

Após essa breve análise, buscar-se-á fazer uma correlação entre as normas tributárias ambientais indutoras e a redução da produção dos resíduos sólidos, tendo como ferramenta a utilização da taxa de coleta de lixo com finalidade ecológica. Utilizar-se-á, como técnica de pesquisa, a revisão bibliográfica, tanto da doutrina brasileira como estrangeira sobre tributação ambiental. Partir-se-á de uma perspectiva econômica vinculada à responsabilidade compartilhada, sob a ótica constitucional e infraconstitucional, para a utilização dessa ferramenta.

Ao final, a hipótese se encaminhará no sentido de provar que a adoção individualizada da regulação direta tem se mostrado ineficaz para os fins pretendidos. A anuência de uma política pública adequada, bom como da indução natural a um comportamento ambientalmente desejável, têm reduzido o alcance e a eficácia desses mecanismos. Em razão dessa evidência, defende-se a adoção crescente de instrumentos econômicos, como método mais eficiente para a regulação indireta de condutas ecologicamente adequadas

\section{A CRISE AMBIENTAL A NOVA ORDEM JURÍDICO-ECOLÓGICA CONSTITUCIONAL}

Nas últimas décadas, as transformações sociais e o desenvolvimento econômico tem sido os principais fatores da degradação dos ecossistemas e instalação de uma verdadeira crise ecológica no planeta. Esse fenômeno acarretou a elevação dos riscos ambientais para a sociedade atual e, principalmente, para as futuras gerações. O nível de degradação da natureza, 
em grande medida, é resultante dos modos de produção e consumo. Os danos ao meio ambiente são estimulados por fatores como: desenvolvimento econômico, crescimento populacional, colapso na urbanização dos grandes centros e revolução tecnológica. Para Cunha e Rangel (2016, p. 22-23), a degradação ambiental é um dos maiores problemas a serem enfrentados pela sociedade e governantes. Transformou-se em um problema transnacional resultante da devastação da biodiversidade, destruição da qualidade de vida dos seres humanos e do agravamento das desigualdades sociais.

Nesse cenário de devastação ecológica, um dos maiores desafio é a urgente redução dos impactos ao meio ambiente, gerados pela absurda quantidade de resíduos produzidos diariamente nas cidades, sem a devida destinação. Para conter o agravamento desse quadro, impõe-se o desenvolvimento de métodos alternativos para estimular a redução desses resíduos. Sua correta destinação é uma responsabilidade compartilhada entre poder público e sociedade, devendo ocupar posição de destaque nas agendas políticas dos governantes.

Segundo Montero (2014, p. 41), a degradação ambiental decorre do comportamento central e da forma como estão organizados a produção e o consumo na chamada sociedade pós-industrial. Para enfrentar essa problemática, mecanismos próprios da lógica de mercado que começam a ser redimensionados, com a intervenção do Estado. Busca-se, com algumas medidas, o equilíbrio da ordem jurídica da defesa do meio ambiente, inclusive mediante tratamento diferenciado, conforme o impacto ambiental dos produtos e serviços, bem como de seus processos de elaboração e prestação (BRASIL, 1988).

O sistema governamental vem tentando criar estratégias eficazes para reduzir o impacto ecológico dessas externalidades negativas ambientais é uma das medidas é motivar a sociedade para proteger os recursos naturais, por meio da mudança de comportamento. Para Callan; Thomas (2016, p.68), são consideradas externalidades ambientais "aquelas que danificam a atmosfera, recursos naturais e a qualidade de vida como um todo"

Os resíduos produzidos pelo consumismo geram externalidades negativas, na medida em que afetam a sociedade. Em razão disso, seus efeitos precisam ser combatidos com medidas eficientes. Essas externalidades advêm de falhas de mercado, citando-se, como exemplo, a falta de incentivos para funcionamento adequado do mercado. É preciso conscientizar os empresários de que não podem visar somente à lucrativa com a venda dos produtos, mas também perceber a necessidade do ganho social. A esse respeito, anotam Callan; Thomas (2016, p. 74):

Embora essas empresas possam estar conscientes dos danos ambientais vinculados à sua produção, não existe incentivo (...) para que elas absorvam tais custos. Se assim o fizessem, afetariam negativamente seus lucros. Seria como se as empresas oferecessem pagar os custos externos em defesa da sociedade. Entretanto, não existe incentivo de mercado para que uma empresa racional incorra em custos maiores do que o necessário, mesmo se for para o bem social.

Os problemas ambientais persistem. Em razão disso, justifica-se a intervenção governamental, de acordo com o texto constitucional para buscar alternativas políticas no sentido de evitar maiores danos à natureza. Essa postura protetiva floresceu, notadamente, nos países que promulgaram suas constituições após a Conferência de Estocolmo, em 1972. Foi um dos primeiros marcos na tentativa de melhor disciplinar o desenvolvimento econômico e a reduzir a degradação ambiental. Como um dos países participantes do evento, o Brasil passou a reconhecer a existência de um direito fundamental ao meio ambiente ecologicamente equilibrado. Em consequência, o meio ambiente vem recebendo atenção especial, de modo que nenhum agente, seja público ou privado, poderá tratá-lo como valor acessório (BENJAMIN, 2010, p. 117-118). 
Na Constituição Federal de 1988, a proteção ambiental, como garantidora da dignidade da pessoa humana, foi elevada ao patamar de direito fundamental. A luta pela garantia de um meio ambiente ecologicamente equilibrado para as futuras gerações passou a ser dever, do poder público e de toda a coletividade. Assim, preceitua o art. 225 da Constituição Federal, consagrando o princípio da solidariedade intergeracional. Como elemento de sustentabilidade, esse princípio tem o objetivo de estabelecer a "equidade entre pessoas vivas no presente e pessoas que nascerão no futuro" (CANOTILHO, 2010).

A juridicidade ambiental ganha o patamar de base fundamental do Estado constitucional. Assim, qualquer projeto que vise ao desenvolvimento econômico e humano, em padrões considerados sustentáveis, deverá ser submetido, necessariamente, à tutela da lei ambiental. Com esse objetivo, foi estabelecida uma nova ordem jurídico-ecológica, composta de duas dimensões: a social e a ambiental. A dimensão social direciona sua preocupação para o indivíduo e a comunidade, considerando-os elementos integrantes de uma mesma realidade político-social (mínimo existencial para uma vida com dignidade). Já a dimensão ambiental preocupa-se com a qualidade de vida como um todo, incluindo-se o ambiente em que a vida humana se desenvolve (mínimo existencial ecológico). Como resultado, exigiu-se uma completa redefinição da concepção de dignidade da pessoa humana quando vista sob a perspectiva dessas duas dimensões (CALIENDO; RAMMÉ; MUNIZ, 2014, p.2).

$\mathrm{O}$ direito de usufruir de um meio ambiente sadio passou a ser reconhecido como materialização dos direitos fundamentais. No entendimento de Canotilho (2010), não cabe à Constituição do país fixar concretamente os instrumentos políticos, econômicos, jurídicos, técnicos e científicos indispensáveis à solução dos problemas ecológico-ambientais. Devese, no entanto, estabelecer diretrizes que possam ser implantadas, de modo a garantir uma melhor qualidade de vida para as presentes e futuras gerações. A efetivação dessa garantia constitucional passa pelo necessário equilíbrio entre o crescimento econômico, a preservação do meio ambiente e a equidade social, que são pilares do desenvolvimento sustentável. A implantação de políticas pública eficientes, a partir do diálogo com as entidades civis, é tarefa que se impõe ao Estado, como forma de garantir a concretização do direito ao meio ambiente equilibrado (THOMÉ, 2014, p. 147-148).

A expressão "desenvolvimento sustentável" alcançou grande visibilidade depois da Conferência das Nações Unidas sobre Meio Ambiente e Desenvolvimento - CNUMAD, realizada na cidade do Rio de Janeiro, em 1992. Desde então, vêm sendo feitas tentativas de implementação de políticas de gestão que contemplem os seus princípios fundamentais. Passou também a ser melhor compreendida a relação entre o desenvolvimento econômico e a manutenção do meio ambiente equilibrado (BARTHOLOMEU, 2011, p. 95).

Seguindo essa linha, a Constituição Federal erigiu, no seu art. 170, VI, a defesa do meio ambiente como princípio da ordem econômica, para fins de assegurar uma vida digna à população e a garantir a justiça social. Para o cumprimento desse comando constitucional, justifica-se a atuação impositiva do Estado (GRAU, 2018, p. 248). Dessa forma, é papel cogente do poder público disciplinar os projetos desenvolvimentistas, no sentido da racionalidade no uso dos recursos naturais. Para cumprimento da ordem constitucional, foi promulgada a Lei no 12.305 , de 03 de agosto de 2010, que institui a política nacional de resíduos sólidos (PNRS). A lei foi, posteriormente, regulamentada pelo Decreto no 7.404, de 23 de dezembro do mesmo ano. Trata-se de um relevante marco normatizador de princípios, objetivos, diretrizes, metas, ações e instrumentos. O texto oferece soluções para o enfrentamento de um dos principais problemas ambientais, sociais e econômicos: o manejo inadequado dos resíduos sólidos.

Para Yoshida (2012, p. 4), a política nacional de resíduos sólidos exerce um importante papel na consecução do federalismo cooperativo brasileiro. Com esse objetivo, traçou 
diretrizes gerais a serem observadas pelos Estados, Distrito Federal e Municípios. Porém, não comprometeu a autonomia dos entes federados que ensejarem criar normas suplementares, como forma de melhor atender as diversidades regionais, bem como as necessidades locais. Com a PNRS, foram priorizados a gestão e o gerenciamento dos resíduos sólidos, a partir de uma atuação compartilhada entre os setores público e privado. Esse compartilhamento é baseado na cooperação, mobilização e participação social, em busca do fortalecimento de uma consciência ambiental. Em consequência, abandonou-se o tradicional controle passivo (mecanismos de comando e controle) e passou a adotar um controle ativo, com maior eficácia na promoção de padrões sustentáveis de consumo e descarte de resíduos.

O legislador federal, ao instituir a política nacional de resíduos sólidos, estabeleceu a seguinte ordem prioritária de gerenciamento e gestão: redução da geração, reutilização, reciclagem, tratamento e disposição final ambientalmente adequada dos rejeitos. Com base nesse modelo, o poder público e a sociedade devem direcionar suas ações para a preservação do meio ambiente. Motivando a intervenção do poder público o panorama de aumento exponencial do consumo e o crescimento acelerado da degradação dos recursos ambientais, este motivado, sobremaneira, pela geração e destinação irregular dos resíduos sólidos. O Estado deve assumir uma postura operacional, mediante a utilização de instrumentos que possam motivar os cidadãos a reduzir seus níveis de consumo e considerar os custos socioambientais decorrentes das suas condutas.

Com efeito, a PNRS conferiu visibilidade à ferramentas utilizadas pelo poder público, por sua maior eficácia na tarefa de promover uma conscientização efetiva em prol da observância das diretrizes nele estabelecidas. Entre esses instrumentos, destacam-se aqueles que, através da concessão de estímulos e vantagens, incorporam o controle ativo na implementação do princípio do poluidor-pagador. De posse dessa ferramenta, procura induzir positivamente mudanças de comportamento, adotando, como estímulo, a extrafiscalidade tributária.

Dessa forma, devem os entes públicos, principais responsáveis pela manutenção do equilíbrio ambiental, abandonar a aplicação do tradicional sistema corretivo-repressivo. Para o controle ambiental, deverão valer-se, entre outras ferramentas, das normas tributárias ambientais indutoras, chanceladas pela PNRS. Trata-se de um instrumento eficiente à motivação de condutas preservacionistas e à redução da geração de resíduos sólidos decorrentes do processo de consumo.

\section{A RESPONSABILIDADE COMPARTILHADA E A CRESCENTE UTILIZAÇÃO DOS INSTRUMENTOS ECONÔMICOS}

A política nacional de resíduos sólidos (Lei no 12.305/2010), foi gestada em meio a uma engajada estrutura legislativa ambiental brasileira, inspirada em uma base constitucional prevista no art. 225 da CRFB. Entre os variados pontos de inovação, destaca-se a implementação de uma gestão compartilhada do meio ambiente, que envolve deveres de cooperação entre o poder público, o setor econômico-empresarial e os demais segmentos da sociedade civil. $\mathrm{O}$ objetivo desse compartilhamento é garantir um gerenciamento integrado dos resíduos sólidos (YOSHIDA, 2012, p. 3).

Para Juras e Araújo (2012, p. 69), a PNRS inovou de forma expressiva quando fixou, entre os seus objetivos fundamentais, a responsabilidade compartilhada também em relação ao ciclo de vida do produto. Ao adotar o princípio do poluidor-pagador, atribuiu responsabilidade pela geração de resíduos sólidos, não somente aos fabricantes dos produtos colocados no mercado, 
mas também aos importadores, distribuidores, comerciantes, consumidores e ao poder público, responsável pelos serviços de limpeza urbana.

Emuma de suasinovações, estabeleceu a corresponsabilidadee agestão compartilhada do meio ambiente entre os poderes estatais dos três níveis federativos e os atores socioeconômicos, com fundamento na solidariedade e equidade intergeracional. Dessa forma, a PNRS se destaca como marco formal da superação da tradicional prática do sistema de comando e controle estatal e suas características protetivo-repressivas. Os acordos setoriais, as modalidades de gerenciamento e os instrumentos econômicos são exemplos desse novo modelo de valorização da auto-organização, participação efetiva e controle por parte da sociedade.

Ao criar a PNRS, o legislador não teve a intenção de retirar a responsabilidade do poder público na gestão de resíduos e repassá-la, integralmente, ao setor privado. Pelo contrário, reforçou a responsabilidade compartilhada do Estado na proteção do meio ambiente, prevista na Constituição Federal, como tarefa primordial na luta pela preservação ecológica. No cumprimento de sua obrigação, os entes públicos devem utilizar instrumentos eficientes capazes de produzir mudanças de comportamento na sociedade. Essas mudanças podem ser estimuladas por intermédio de concessões de vantagens e incentivos àqueles que decidirem proteger o meio ambiente.

A inserção da proteção ambiental na Constituição Federal legitima e vincula a intervenção estatal, com o apoio da iniciativa privada no processo de recuperação dos ecossistemas. Portanto, é dever do poder público atuar de forma enérgica e assertiva em favor da proteção ecológica, sempre visando à preservação de um meio ambiente equilibrado para as presentes e futuras gerações (princípio da equidade intergeracional). Nessa perspectiva, as políticas públicas ambientais podem ser entendidas como o poder estatal necessário para a regulação das atividades sociais e econômicas. Exerce essa prerrogativa através da imposição de limites, da aplicação de punições e da concessão de incentivos e aos particulares, de modo a instituir uma verdadeira ordem pública ambiental. Ao cumprimento do seu dever constitucional de proteção dos ecossistemas, o Estado deve valer-se, basicamente, de duas ferramentas: mecanismos de comando e controle e instrumentos econômicos.

Historicamente, no cumprimento de sua responsabilidade constitucional de garantir um meio ambiente equilibrado, o poder público tem se valido de instrumentos de comando e controle. São medidas de regulação direta, instituídas mediante a fixação de normas, regras, procedimentos e padrões predeterminados para as atividades econômicas. A não observância das determinações legais acarreta sanções de cunho administrativo, como, por exemplo, fixação de padrões, estudos de impacto ambiental, licenciamentos e zoneamento. Porém, conforme assinala Montero (2014, p. 158-159), a adoção da regulação direta tem se mostrado ineficaz para os fins pretendidos. Os custos para sua implementação, a uniformidade das medidas, sem considerar as especificidades dos agentes econômicos, bem como a ausência de uma indução natural a um comportamento ambientalmente desejável, têm reduzido o alcance e a eficácia desses mecanismos.

A política ambiental instituída através de mecanismos corretivo-repressivos, comando e controle foi dominante nas décadas de 1970 e 1980. A partir dos anos de 1990, foi sendo substituída pela adoção de instrumentos econômicos. A mudança foi provocada por diversos fatores, como: a) o reconhecimento das limitações dos governos em geral, bem como dos sistemas tradicionais de comando, controle e regulamentação, em lidar adequadamente com os problemas ambientais, apesar da imposição de custos econômicos consideráveis; b) a necessidade de adotar mecanismos para internalizar os custos ambientais nos preços de bens e serviços, como forma de melhor implementar o princípio do poluidor-pagador; c) a 
necessidade de integrar a política ambiental a outras políticas públicas: agricultura, indústria de transporte, turismo, emprego e renda (LEITE et al., 2018, p. 04).

A utilização de instrumentos econômicos, para fins de proteção do meio ambiente, tem se mostrado eficiente no combate às externalidades negativas, resultantes dos danos ecológicos causados pelos processos produtivos e pela própria utilização de recursos naturais. Constatou-se, portanto, uma maior eficiência na concretização do princípio constitucional do poluidor-pagador. Há execução da gestão responsável dos resíduos sólidos, o Estado deve adotar políticas públicas com base nos mecanismos de comando e controle. Para tanto, deve valer-se, principalmente, de instrumentos econômicos, com vista à redução do volume dos resíduos. Com a aplicação efetiva do princípio do poluidor-pagador, os custos ambientais passarão a ser assumidos pelos agentes econômicos (JURAS;ARAÚJO, 2012, p. 61).

A lei da política nacional de resíduos sólidos fixou um rol exemplificativo de instrumentos que devem ser utilizados para a redução da produção descontrolada de resíduos sólidos urbanos, bem como para sua adequada destinação. Um deles é a concessão de incentivos fiscais, financeiros e creditícios. Para Ribeiro; Ribas (2013, p. 13), essa medida possibilita que os entes públicos instituam normas para ampliar os instrumentos econômicos a serem usados na reutilização, tratamento e reciclagem dos resíduos.

Com relação aos instrumentos econômicos para a redução e o tratamento de resíduos

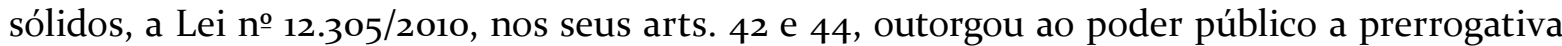
de instituir medidas indutoras às condutas de preservação do meio ambiente na execução de processos produtivos. Esse estímulo, conforme preceitua a citada lei, poderá ser concretizado através de normas que objetivem a concessão de incentivos fiscais, financeiros e creditícios. Nesse tipo de medida, inclui-se o uso de tributos para o alcance das diretrizes e objetivos fixados na PNRS, conforme lembra Barreira (2012, p. 145-146). Montero (2014, p. 165) faz referência à tentativa de classificar as categorias de instrumentos econômicos que podem ser utilizados pelo Estado, para fins de proteção ambiental. Com esse objetivo a Organização para Cooperação e Desenvolvimento Econômico - OCDE fixou a seguinte divisão: sistemas de depósito/reembolso, criação de mercados, medidas de apoio ou ajuda financeiras e tributos.

Dentro desse rol de instrumentos econômicos de maior relevância na atualidade, destaca-se a adoção de normas tributárias indutoras com finalidade socioambiental. Essas normas podem ter grande eficácia, especialmente quando alinhadas com o dever do poder público de instituir um melhor gerenciamento dos resíduos sólidos. Trata-se de medida que extrapola os fins econômicos da exação, para mirar na verdadeira mudança de hábitos por meio da educação ambiental, administrando com eficácia, os custos dos processos produtivos.

\section{NORMAS TRIBUTÁRIAS AMBIENTAIS INDUTORAS PARA A REDUÇÃO DA GERAÇÃO DOS RESÍDUOS SÓLIDOS}

Conforme já referido, o Estado deve assumir seu papel constitucional de garantia da preservação do meio ambiente, do crescimento ecoeficiente e da equidade social, alicerces do desenvolvimento sustentável. Para tanto, precisa lançar mão de instrumentos econômicos, a exemplo da extrafiscalidade dos tributos. Com essa medida, pode suprir a baixa eficiência que os mecanismos de comando e controle têm demonstrado na proteção ambiental (MONTERO, 2014, p. 158-161).

Para Barreira (2012, p. 141), o tributo utilizado como instrumento de implementação de políticas públicas ambientais, como forma de desenvolver a corresponsabilidade dos contribuintes, atende a ordem econômica constitucional. Assim, com fundamento nos arts. 
170, VI, e 225, da Constituição Federal, os poderes constituídos podem e devem instituir exações ambientais que promovam, através da extrafiscalidade, comportamentos positivos e desestimulem atitudes danosas ao meio ambiente. Inquestionavelmente, a adoção da extrafiscalidade tributária, em favor da proteção dos ecossistemas, é a melhor alternativa para a consecução efetiva do princípio do poluidor-pagador. O principal objetivo é estimular condutas que visem à internalização compulsória das externalidades ambientais negativas geradas pelo próprio sistema produtivo. Evita-se, em consequência, a socialização dos custos ecológicos da produção, fato gerador de injustiças socioambientais. (CALIENDO, RAMMÊ; MUNIZ, 2014, p. 6).

Existem diversas técnicas que permitem a indução de comportamentos ambientalmente adequados. Uma delas é tornar a carga fiscal mais branda, ou desestimular a prática de condutas degradadoras do meio ambiente pela adoção de taxas tributárias mais gravosas. São exemplos de estratégias indutoras de exações: utilização de alíquotas progressivas ou seletivas, isenção fiscal, redução de alíquotas, aproveitamento de créditos fiscais e redução da base de cálculo.

Inserção de critérios ambientais na tributação ordinária e criação de "incentivos fiscais verdes" são outras formas de indução de condutas que podem atender os objetivos da política nacional de resíduos sólidos. Especial destaque deve ser dado à geração, tratamento e destinação ambientalmente adequada desses resíduos. A previsão da extrafiscalidade na referida norma é considerada um estímulo a comportamentos direcionados à tutela da proteção ambiental. Há ainda outros instrumentos relevantes, a exemplo do poluidor-pagador, protetor-recebedor, desenvolvimento sustentável e ecoeficiência (MAIA; SILVA, 2017, p. 6o-61).

Está provado que uma norma tributária ambiental tem o potencial de induzir os contribuintes optarem por uma conduta em prol da preservação do meio ambiente, com a concessão de isenções ou imposição de um gravame. Essa medida pode ser direcionada para fins de uma melhor gestão e destinação dos resíduos sólidos. Esse instrumento indutor pode ser utilizado em qualquer espécie de exação, inclusive nas taxas (LIMA, 2014, p. 156). Em razão da sua grande abrangência estrutural, as taxas possuem destacada relevância para fins ambientais, quando utilizadas com escopo indutor. Exemplo disso são as taxas de coleta de lixo, que devem assumir um caráter extrafiscal incentivador de comportamentos voltados à proteção do meio ambiente, de modo a atender os objetivos e diretrizes da política nacional de resíduos sólidos (TAPIASSU, 2006, p. 141).

Os municípios brasileiros possuem competência primária em matéria de resíduos sólidos. No entanto, vêm aplicando uma função exclusivamente retributiva (arrecadatória) às taxas exigidas aos beneficiários dos serviços de limpeza urbana e manejo de resíduos. Essa referida exação, de forma recorrente, encontra-se desprovida de quaisquer aspectos de extrafiscalidades capazes de motivarem, efetivamente, comportamentos ambientalmente aceitáveis. É oportuno lembrar que a lei da política nacional de resíduos sólidos instituiu o plano municipal de gestão integrada de resíduos sólidos. Trata-se de condição indispensável para que os entes municipais tenham acesso aos recursos do governo federal. Ao município cabe estabelecer o cálculo dos custos e forma adequada de cobrança pelos serviços de limpeza urbana e manejo de resíduos sólidos.

Cita-se, a propósito, a Lei no $11.445 / 2007$, que fixa as diretrizes nacionais para o saneamento básico. Estabelece, no seu art. 29, II, que os serviços públicos de limpeza urbana e manejo de resíduos sólidos deverão ter sustentabilidade econômico-financeira assegurada por meio da cobrança de taxas, tarifas ou preços públicos, conforme o regime da prestação do serviço ou das suas atividades. No art. 30, III, destaca a proteção ao meio ambiente como um dos fatores relevantes na estrutura da cobrança pelos serviços de saneamento básico. Dessa forma, a utilização das taxas referentes às questões ambientais obtiveram a efetivação da 
política nacional de resíduos sólidos (Lei no 12.305/2010). Essa utilização apresenta-se como ferramenta relevante do poder público na indução de condutas comportamentais proativas, direcionadas à minoração dos danos ambientais.

A consequência disso é que, na composição da cobrança pelos serviços de manejo dos resíduos sólidos, não se deve considerar unicamente a arrecadação de valores suficientes para cobrir os custos da sua adequada disponibilização. Cabe ao poder público municipal estimular a população a adotar práticas que propiciem à redução, na fonte, do volume de resíduos gerados. Fazendo também seu manejo adequado. A citada Lei no 11.445/2007, autoriza que as taxas ou tarifas decorrentes da prestação dos serviços de manejo dos resíduos sólidos levem em consideração o volume médio coletado por habitante ou domicílio. Uma vez adotada essa medida, a composição da cobrança dos serviços de coleta de lixo teria um alto potencial para estimular a redução da geração de resíduos sólidos, sendo efetivamente concretizado o postulado constitucional do poluidor-pagador.

Deve-se evitar a tradicional e ineficaz repartição dos custos entre os agentes que demandam o serviço de limpeza urbana e coleta de lixo. É preciso implementar instrumentos de desestímulo à geração de resíduos. Uma das hipóteses é a exploração do caráter extrafiscal da exação que visa a remunerar os referidos serviços. Para tanto, podem ser concedidos incentivos fiscais àqueles contribuintes que manteram seus níveis de agressão ao meio ambiente.

Portanto, o poder público, no exercício do seu dever constitucional, não deve utilizar apenas os tradicionais mecanismos de comando e controle, para punir aqueles que descumprirem as normas protetivas do meio ambiente. Deverá também valer-se de instrumentos econômicos, a exemplo da extrafiscalidade tributária, como forma de estimular os contribuintes a adotarem posturas alinhadas com a necessária qualidade ambiental. Dessa forma, aqueles que adotarem condutas preservacionistas deverão ser beneficiados com uma menor carga fiscal em relação ao grupo mais agressivo ao meio ambiente (BARREIRA, 2012, p. 169).

A política nacional de resíduos sólidos recepciona a mudança de paradigma do mundo moderno. A mais importante foi migrar da regulação direta para a indireta, por mostrarse mais eficiente. A Lei no 12.305/2010 chancelou ao Estado a prerrogativa de instituir medidas indutoras às condutas de preservação do meio ambiente, especialmente, por parte dos empresários nos processos produtivos. Para tanto, deve conceder às classes produtivas incentivos fiscais, financeiros e creditícios.

\section{CONSIDERAÇÕES FINAIS}

Constata-se que, historicamente, a sociedade tem adotado uma postura de descompromisso com a conservação ao meio ambiente, levando a uma dupla reflexão: como se chegar a esse grau de degradação; o que se deve fazer para recuperar a natureza degradada. É inegável que, ao longo das últimas décadas, ocorreu uma verdadeira revolução nos modos de produção e consumo. Ela foi estimulada por fatores como o desenvolvimento econômico, o desenfreado crescimento populacional, a inadequada urbanização nos grandes centros e a inovação tecnológica. Como consequência ocorreu o aumento da degradação do meio ambiente, com a eclosão de uma verdadeira crise ecológica, notadamente, no inadequado dos resíduos sólidos.

Para fazer frente à ineficiência do poder público e da sociedade como um todo, após um logo período de tramitação no Congresso Nacional foi promulgada a Lei no 12.305/2010, que dispõe sobre a política nacional de resíduos sólidos. Esse diploma legal foi criado para 
regulamentar o comando constitucional em matéria ambiental. Entre outras medidas, promoveu a responsabilidade compartilhada entre os entes públicos e os segmentos socioeconômicos, na gestão integrada e no gerenciamento ambientalmente adequado dos resíduos sólidos.

A lei conferiu importante estímulo à auto-organização, à cooperação, à mobilização e à participação de todos os segmentos da sociedade, na preservação do meio ambiente. Esse novo modelo abandonou o tradicional o controle passivo-repressivo, materializado através dos mecanismos de comando e controle. Em substituição, criou instrumentos que induzem positivamente as mudanças de comportamento da sociedade, através da concessão de benefícios àqueles que protegem o meio ambiente. No conjunto dessas medidas indutoras das condutas de preservação da natureza e redução da geração de resíduos sólidos, destaca-se a extrafiscalidade tributária como um dos poderosos instrumentos econômicos de proteção ambiental. A norma tributária indutora, quando utilizada em prol da proteção dos ecossistemas, leva à consecução efetiva do princípio do poluidor-pagador.

A adoção da extrafiscalidade tributária ganha relevo como medida de estímulo a comportamentos ambientalmente adequados às diretrizes da política nacional de resíduos sólidos. A dimensão indutora das exações está prevista na Lei oㅡ 12.305/2010, que estabelece como um dos seus objetivos primordiais o estímulo a condutas que resultem na tutela da proteção ambiental. Exemplo disso é a aplicação da taxa de coleta de resíduos sólidos. Com ela, evita-se a injusta repartição dos custos entre os contribuintes, que demandam o serviço de limpeza urbana e coleta de lixo. Além dessa medida, é preciso implementar instrumentos de desestímulo à geração de resíduos, como a extrafiscalidade das exações. Aplica-se, por conseguinte, o princípio do poluidor-pagador, estabelecendo-se a internalização das externalidades ambientais negativas.

Em conclusão, pode-se afirmar que a PNRS potencializou a substituição dos mecanismos de comando e controle (normas corretivo-repressivas). Através do compartilhamento de responsabilidades ambientais no ciclo de vida dos produtos, estimulou o poder público a adotar instrumentos econômicos capazes de melhor incentivarem a mobilização social e a mudança de comportamentos na corresponsabilidade de preservação dos ecossistemas. Exemplo disso é a utilização da taxa de coleta de resíduos sólidos, como forma de estimular a redução na geração desses resíduos, bem como na correta destinação.

Infelizmente, os municípios brasileiros, em grande maioria, ainda não estão aplicando as novas formas de cobrança pela prestação dos serviços de limpeza urbana e coleta de lixo, deixando de explorar o potencial indutor da exação. Portanto, é necessário que todos os entes federados abandonem, de uma vez por todas, o antigo modelo repressivo e passem a adotar ferramentas que conduzam à mudança de mentalidade da sociedade em favor da conservação do meio ambiente.

\section{REFERÊNCIAS}

ANTUNES, Paulo de Bessa. Direito ambiental. 17. ed. São Paulo: Editora Atlas, 2017.

BARREIRA, Fábio Nieves. Aspectos tributários. In: JARDIM, Arnaldo; YOSHIDA Consuelo; MACHADO, José Valverde (Org.). Política nacional, gestão e gerenciamento de resíduos sólidos. São Paulo: Manole, 2012. 
BARTHOLOMEU, Daniela Bacchi. Desenvolvimento Sustentável e a Questão dos Resíduos Sólidos. In: BARTHOLOMEU, Daniela Bacchi; CAIXETA-FILHO, José Vicente (Org.). Logística ambiental de resíduos sólidos. São Paulo: Atlas, 2011.

BENJAMIN, Antônio Herman. Constitucionalização do ambiente e ecologização da Constituição brasileira. In CANOTILHO, José Joaquim Gomes; LEITE, José Rubens Morato (Orgs.). Direito constitucional ambiente brasileiro. São Paulo: Saraiva, 2010.

CALIENDO, Paulo; RAMMÊ, Rogério; MUNIZ, Veyzon. Tributação e sustentabilidade ambiental: a extrafiscalidade como instrumento e proteção do meio ambiente. Revista dos Tribunais de Direito Ambiental online. vol. 76, out-dez 2014.

CALLAN, Scott J.; THOMAS, Janet M. Economia ambiental: aplicações, políticas e teoria. 2.ed. São Paulo: Cengace Learning, 2016.

CANOTILHO, JoséJoaquim Gomes. OPrincípio da sustentabilidade como princípio estruturante do Direito Constitucional. Tékhne, Barcelos, n. 13, p.07-18, jun. 2010. Disponível em <http:// www.scielo.mec.pt/scielo.php?script=sci_arttext\&pid=S1645-99112010000100002\&lng=pt\&nr $\mathrm{m}=\mathrm{iso}>$. Acesso em 02 dez. 2019.

CUNHA, Belinda Pereira da; RANGEL, Ana Celecina Lucena da Costa. A crise contida em outras crises: perspectivas históricas e político-sociais da crise ambiental atual. In: CUNHA, B. P. (Org.). Crise ambiental. Curitiba: Appris, 2016.

GRAU, Eros Roberto. A ordem econômica na Constituição de 1988. 19. ed. São Paulo: Malheiros, 2018.

JURAS, Ilidia da A. Garrido Martins; ARAÚJO, Suely M. Vaz Guimarães de. A responsabilidade compartilhada pelo ciclo de vida do produto. In JARDIM, Arnaldo; YOSHIDA Consuelo; MACHADO, José Valverde (Orgs.). Política nacional, gestão e gerenciamento de resíduos sólidos. São Paulo: Manole, 2012.

LEITE, Acácio Zuniga et al. Reforma tributária ambiental: perspectivas para o Sistema Tributário Nacional. Texto para discussão. Plataforma política social. Fevereiro de 2018. Disponível em http://sindifisco-pa.org.br/wp-content/uploads/2018/o5/TD_18.pdf. Acesso em 15 ago. 2019.

LIMA, Isabel Arruda Matheos de. Normas tributárias indutoras ambientais. 331f. Tese (Doutorado em teoria e dogmática do direito). Faculdade do Recife/Universidade do Estado de Pernambuco, Recife, 2014.

MAIA, Fernando Joaquim Ferreira; SILVA, Rafaela Patrícia Inocêncio. A aplicação da extrafiscalidade à Política Nacional de Resíduos Sólidos examinada pela perspectiva de Enrique Leff. Revista Acadêmica da Faculdade de Direito do Recife. Recife. vol. 89, no o1, p. 51-71, jan-jun 2017.

MONTERO, Carlos Eduardo Peralta. Tributação ambiental: reflexões sobre a introdução da variável ambiental no sistema tributário. São Paulo: Saraiva, 2014. 
RIBEIRO, Maria de Fátima; RIBAS, Lídia Maria Lopes Rodrigues. Políticas públicas de incentivos fiscais como instrumentos da política nacional de resíduos sólidos. In RIBEIRO, D. M.; BENACCHIO, M. (Orgs.). Direitos sociais e políticas públicas II. XXII Encontro Nacional do CONPEDI / UNINOVE. Florianópolis: FUNJAB, 2013. Disponível em <http:// www.publicadireito.com.br/publicacao/uninove/livro.php?gt=113>. Acesso em: 13 jan. 2019.

ROMEU, Thomé. O princípio da vedação do retrocesso ambiental no contexto da sociedade de risco. Salvador: Editora Juspodvim, 2014.

TAPIASSU, Lise Vieira da Costa. Tributação ambiental: a utilização de instrumentos econômicos e fiscais na implementação do direito ao meio ambiente saudável. Rio de Janeiro: Renovar, 2006.

YOSHIDA, Consuelo. Competência e as diretrizes da PNRS: conflitos e critérios de harmonização entre as demais legislações e normas. In JARDIM, Arnaldo; YOSHIDA Consuelo; MACHADO, José Valverde (Orgs.). Política Nacional, gestão e gerenciamento de resíduos sólidos. São Paulo: Manole, 2012. 